\title{
A Multi-mediation Model on the Relations of Bullying, Victimization, Identity, and Family with Adolescent Depressive Symptoms
}

\author{
Anne van Hoof - Quinten A. W. Raaijmakers • \\ Yolanda van Beek • William W. Hale III • \\ Liesbeth Aleva
}

Received: 9 July 2007 / Accepted: 28 November 2007 / Published online: 7 December 2007

(C) The Author(s) 2007

\begin{abstract}
This study investigated a multi-mediation model of the relationship between bullying behavior, peer victimization, personal identity, and family characteristics to adolescent depressive symptoms in 194 high school students, 12-18 years of age. In the first model, peer victimization mediated the relation between bullying behavior and depressive symptoms. In the second model, personal identity mediated the relation between peer victimization and depressive symptoms. In the final model, the two mediation models were combined. The relative influence of family characteristics on all variables in the two mediation models was studied using structural equation modeling. The results supported both mediation models and confirmed the influence of family characteristics on all variables in the mediation models. This study indicates that victimization by one's peers has consequences for adolescents' psychological health when their personal identity is affected. In addition, the study was able to model several processes in which family characteristics were related to
\end{abstract}

A. van Hoof $(\bowtie) \cdot$ Y. van Beek · L. Aleva

Department of Developmental Psychology, Utrecht University,

P.O. Box 80140, 3508 TC Utrecht, The Netherlands

e-mail: a.vanhoof@uu.nl

Y. van Beek

e-mail: y.vanbeek@uu.nl

L. Aleva

e-mail: a.e.aleva@uu.nl

Q. A. W. Raaijmakers · W. W. Hale III

Department of Adolescent Studies, Utrecht University,

P.O. Box 80140, 3508 TC Utrecht, The Netherlands

e-mail: Q.A.W.Raaijmakers@uu.nl

W. W. Hale III

e-mail: b.hale@uu.nl adolescent depressive symptoms. Moreover, the final combined model (in which the two mediation models and the influence of family characteristics on all variables were confirmed) explained half of the variance in adolescent depressive symptoms.

Keywords Peer victimization - Depressive symptoms · Personal identity $\cdot$ Bullying behavior · Family

\section{Introduction}

Problems in social relationships frequently co-occur with adolescent depressive symptoms (Nolan et al. 2003; Van Beek et al. 2006). One prominent problem in social relationships related to adolescent depression is being a victim of bullying behavior by peers, also referred to as peer victimization (Bond et al. 2001; Hawker and Boulton 2000; Schwartz et al. 2005). In their review of peer victimization and depressive symptoms, Hawker and Boulton (2000) have called for research designs that address more complex questions concerning the relationships between peer victimization and depressive symptoms. Likewise, in their review of risk factors for adolescent depression, Garber and Flynn (2001) have called for research designs that simultaneously include risk factors for depressive symptoms and that also make use of complex mediation models.

The current study follows the suggestions of Hawker and Boulton (2000) and of Garber and Flynn (2001) to study multivariate models of depression that include complex mediations. The aim of the present study is to determine the relative influence of bullying behavior, peer victimization, personal identity, and family characteristics on the vulnerability for adolescent depressive symptoms. It 
builds on two recent studies that examined mediation models assessing the relative contribution of risk factors as well as the mediating factors for vulnerability for adolescent depression. The first study is that of Van der Wal et al. (2003). Van der Wal et al. hypothesized that peer victimization is a mediating process in the relationship between bullying behavior and depressive symptoms. The second is a study by Troop-Gordon and Ladd (2005) who tested models in which the association between peer victimization and depressive symptoms was mediated by self-cognitions. The present study combined the hypotheses of Van der Wal et al. (2003), and Troop-Gordon and Ladd (2005), and consisted of simultaneously testing these two mediation models. In addition, the relative effect of family characteristics on all variables in the two mediation models was estimated.

In accordance with the findings of Van der Wal et al. (2003), in this study the first mediation model hypothesized that peer victimization mediates the relation between bullying behavior and depressive symptoms. In accordance with the results of Troop-Gordon and Ladd (2005), the second mediation model hypothesized that personal identity mediates the relation between peer victimization and depressive symptoms. Finally, both mediation models were combined and the relative influence of family characteristics on all variables in the two mediation models was tested.

Bullying Behavior, Peer Victimization, and Depressive Symptoms

Empirical studies on the relation between bullying behavior and depressive symptoms have not been clear-cut. While some studies have found a modest association (e.g., Bosworth et al. 1999; Slee 1995), other studies have reported statistically insignificant relations (e.g., Juvonen et al. 2003; Solberg and Olweus 2003). Thus, empirical studies on the relation between bullying behavior and depressive symptoms have shown that this relation is either absent or weak.

In contrast to bullying behavior, peer victimization appeared to be systematically related to depressive symptoms both cross-sectionally (Hawker and Boulton 2000), and longitudinally (Bond et al. 2001; Schwartz et al. 2005), with peer victimization predicting depressive symptoms. Moreover, in their review of cross-sectional studies on the relation between peer victimization and seven indicators of psychosocial maladjustment, Hawker and Boulton (2000) demonstrated that depression was the most important indicator. Empirical research has clearly shown that peer victimization is systematically related to depressive symptoms. Furthermore, when compared with its relation with other indicators of maladjustment, peer victimization is more strongly related to depressive symptoms than to, for instance, loneliness or anxiety.

In addition to studying these two variables on their own, peer victimization and bullying behavior can be studied together in respect to their individual relative influence on depressive symptoms. Van der Wal et al. (2003) suggested that the depressive symptoms among children who bully are mainly the result of their being bullied themselves. They argued that it remains unclear whether the association between bullying behavior and depression still holds whenever this relationship is controlled for the level of being bullied. The authors tested this hypothesis in a study of Dutch primary school children. They found that the statistically significant relation between bullying behavior and depressive symptoms disappeared as soon as it was corrected for both being bullied and certain socio-demographic variables, such as gender, age, and family structure. However, since Van der Wal et al. tested their hypothesis by simultaneously controlling for being bullied and socio-demographic variables, the relative contribution of each variable to the disappearance of the relationship between bullying and depressive symptoms remains unclear. Furthermore, it is not certain whether their findings from children also apply to adolescents.

The idea that the relation between bullying behavior and depressive symptoms is the result of being also a victim of bullying behavior has to some extent been tested in earlier studies. These studies investigated mean differences in depressive symptoms between persons categorized in one of the following four groups: bullies, victims, being simultaneously a bully and a victim (bully/victims), or not being involved (e.g., Fekkes et al. 2004; Haynie et al. 2001; Kaltiala-Heino et al. 2000; Kumpulainen and Rasanen 2000). If depressive symptoms among those who bully are the result of their being bullied themselves, then the bully/victim category should be related to depression, and the bully category should not. Empirical results supported the first assumption, but not the second. A systematic finding across these studies has indeed been that whenever a bully/victim category was included, it either showed the highest level of depressive symptoms (e.g., Haynie et al. 2001; Kaltiala-Heino et al. 2000), or it showed a level that was comparable to that of the victim category (Craig 1998; Juvonen et al. 2003).

However, the inclusion of a bully/victim category has not always led to the absence of a relationship between the bully category and depression. In these studies, participants categorized as bullies demonstrated either a level of depressive symptoms that was similar to noninvolved participants (e.g., Fekkes et al. 2004) or a higher level of depressive symptoms than the noninvolved (e.g., Haynie et al. 2001; Kaltiala-Heino et al. 2000). One possible 
reason for the bully category to be related to depressive symptoms is that these categories were formed using cutoff points. As a result, the bullying category still includes individuals who are, to some extent, being bullied by their peers. Thus, the question still remains whether the relation between bullying and depressive symptoms really does disappear after it has been controlled for all levels of peer victimization.

Peer Victimization, Personal Identity, and Depressive Symptoms

In their review of the literature on the relationship between peer victimization and psychosocial maladjustment, Hawker and Boulton (2000) not only examined factors of psychological well-being, such as anxiety and depression, but also factors of self-cognitions such as self-concept and selfesteem. More recently, research on the relation between peer victimization, psychological well-being, and self-cognitions has shifted to models in which self-cognitions partially mediate the relation between peer victimization and psychological well-being (e.g., Troop-Gordon and Ladd 2005). These models are based on the idea that interpersonal relations and cognitive processes interact in ways that either prevent or worsen maladjustment. Through the process of internalization, bullying by peers can influence the individual's self-cognitions. These self-cognitions, in turn, can make the adolescent vulnerable for depressive symptoms.

Until now, the models in which self-cognitions partially mediate the relation between peer victimization and depressive symptoms have not been studied in adolescent samples. Moreover, these models have the disadvantage of contamination between the mediator (self-cognitions) and the dependent variable (depressive symptoms), since negative self-cognitions are part of the definition of depressive symptoms (e.g., Sitarenios and Kovacs 1999). An alternative mediator that is particularly relevant to adolescents, and that is distinct from the definition of depressive symptoms is the formation of a personal identity. Whereas self-cognitions, such as self-perception and self-esteem, refer to the assessment, description, understanding, evaluation or complexity of the self, a personal identity consists of a sense of continuity, of remaining the same under various conditions. More specifically, personal identity, which emerges in adolescence, is defined as a sense of temporal-spatial continuity, which is a sense of being the same person through time and different contexts (e.g., Côté and Levine 1987; Van Hoof and Raaijmakers 2002).

Adolescents function in different contexts, such as school, home or leisure, and they have an understanding of their interests, competences, investments, and functioning in these contexts. The adolescent's functioning in a specific context may to a certain extent be context-bound. In order to achieve a sense of temporal-spatial continuity, these context-specific identities have to be bridged. Despite the fact that individuals may be more or less aware of the different identities they express in different contexts, they still remain unaware of how or how well their contextspecific identities are integrated and how this integration changes through time (e.g., Snarey et al. 1983). Therefore, the formation of a personal identity requires the adolescent's context-specific identities to be integrated into a coherent profile, which provides the adolescent with a sense of being the same person through time and context. Such a coherent profile ultimately contributes to the person's general psychological well-being (e.g., Van Hoof and Raaijmakers 2002, 2003).

Modeling personal identity as a mediator between peer victimization and psychological well-being assumes that victimization by peers only affects psychological wellbeing in situations when peer victimization affects the adolescent's sense of personal identity. In other words, adolescents' psychological well-being is affected only in those situations when being bullied negatively influences the integration of context-specific identities. Difficulties in integrating context-specific identities can occur when the adolescent is not able to sense being the same person in all contexts in which he or she participates. For example, research has shown that being victimized by peers influences school functioning. Adolescents who are victimized by their peers tend to dislike and avoid school (Rigbee 2003). Peer victimization has also been related to poor academic functioning (Juvonen et al. 2000; Schwartz et al. 2005). Thus, when an adolescent who is victimized by peers is not able to display his or her competencies at school, or pursue his or her interests, the adolescent may have difficulties displaying a personally relevant school identity. This change in school identity jeopardizes its integration with the adolescent's home identity and leisure identity, thereby endangering his or her personal identity.

\section{The Importance of Family Characteristics}

Family functioning has been studied in relation to peer victimization, bullying behavior, identity and depressive symptoms. In these studies, two characteristics of family functioning are indicators of optimal functioning: family cohesion and family affect. In our study we will examine family cohesion and family affect in relation to adolescent peer victimization, bullying behavior, personal identity, and depressive symptoms.

Most studies on the relation between family cohesion, bullying behavior and peer victimization have compared bullies, victims, bully/victims or noninvolved on their 
mean differences in family cohesion (e.g., Berdondini and Smith 1996; Bowers et al. 1992; Stevens et al. 2002). These studies have consistently found that bullies showed a lower mean level of family cohesion than victims or noninvolved children. The mean score on family cohesion of victims and bully/victims did not differ from that of the noninvolved. However, these studies have exclusively focused on primary school aged children. The question is whether it is possible to generalize these results to adolescents. Furthermore, it remains unclear whether similar results would be obtained if bullying behavior or peer victimization were viewed as a continuum, taking into account not only the extremes but rather the full range of bullying behavior and peer victimization.

Family affect has been related to both bullying behavior and peer victimization. The more family warmth and affection adolescents reported, the less they reported being bullied or showing bullying behavior (Rigbee et al. 1999). Likewise, bullies and bully/victims showed a lower mean level of family affect than those who were noninvolved. For girls, the mean level of family affect was also lower for the victims than for the noninvolved (Rigby 1994). In sum, empirical studies show that family cohesion and family affect are protective influences in the development of bullying behavior. Studies do not consistently show that family cohesion and family affect are protective influences for peer victimization.

Only a few studies have focused on the association of cohesion and affect with identity development. In these studies, a moderately strong relation between family environment and identity formation was observed (Adams et al. 2006; Matheis and Adams 2004). A supportive family environment characterized by emotional attachments tends to facilitate identity development. Thus far, the relation between family environment and personal identity as a sense of temporal-spatial continuity has not yet been studied. It is, however, likely that family cohesion and family affect also positively contribute to personal identity. A supportive family encourages the adolescent to express his or her identity in the contexts of home, school and leisure time. As a result, a supportive family facilitates a sense of identity continuity through time and contexts.

Perceived lack of family cohesion or parental attachment predicts the onset of depression in adolescents, or increases in depressive symptoms during adolescence (for a review, see Garber and Flynn 2001). Family environment is only one of several factors influencing vulnerability to depression. Garber and Flynn (2001) stressed the importance of studying multivariate vulnerability models which include complex mediations, as opposed to simple vulnerability models that only determine the independent contribution of individual risk factors. A multivariate vulnerability model allows for the examination of the relative importance of family characteristics as compared to other risk factors.

\section{The Present Study}

The first aim of this study is to examine whether a relationship between bullying behavior and depressive symptoms still remains after controlling for the effect of peer victimization. It is hypothesized that peer victimization mediates the relationship between bullying behavior and depressive symptoms. In other words, it is assumed that the prevalence of depressive symptoms among adolescents who bully is primarily the result of being bullied themselves. This hypothesis fills a gap in the research on the mediating function of peer victimization because it combines three aspects that were absent in previous research. First, it examines this hypothesis in a sample of adolescents. Second, continuous measures are used to assess these adolescents' bullying behavior and peer victimization in order to test the mediating function for all levels of peer victimization. And, thirdly, the hypothesis is tested by excluding demographic characteristics of the respondents with the aim of determining the unique contribution of being bullied.

The second aim of this study is to determine whether personal identity mediates the relation between peer victimization and depressive symptoms. It is hypothesized that personal identity at least partially mediates the relation between peer victimization and depressive symptoms. Previous research has tested models in which self-cognitions fulfilled the mediating function between peer victimization and depressive symptoms. In the present study, personal identity is considered more appropriate because of its relevance for the adolescent developmental stage and because, in contrast to self-cognitions, it is not part of the operational definition of depressive symptoms.

The third and final aim of this study is to investigate the relative importance of family cohesion and family affect in the proposed relations between peer victimization, bullying behavior, personal identity and depressive symptoms. It is hypothesized that family characteristics are related to all factors. However, the question remains whether family characteristics are still directly related to depressive symptoms after controlling for its relations to peer victimization, bullying behavior, and identity. The current study contributes to the knowledge on adolescent vulnerability for depressive symptoms by examining a multivariate vulnerability model that includes complex mediations.

The three aims of this study are combined into one model (see Fig. 1). The full model consists of two mediation models and paths that represent the possible effects of family characteristics. 


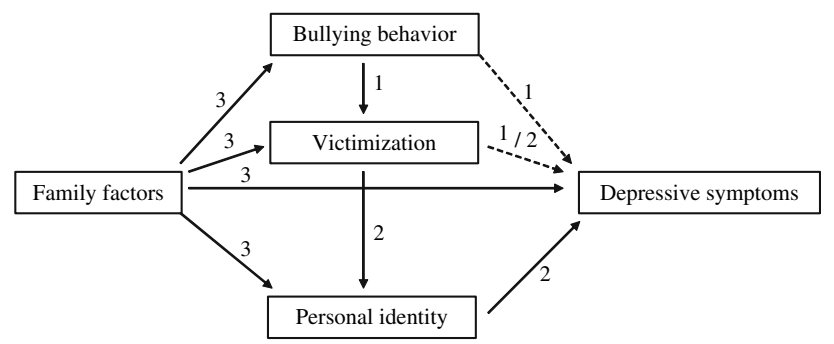

Fig. 1 Hypothesized relations between family factors, bullying, identity and depressive symptoms. Number 1 refers to mediation model 1, number 2 refers to mediation model 2. Number 3 refers to the influence of family. Broken lines indicate mediated paths in the full model

\section{Method}

\section{Participants}

About 194 high school students from grades 9 to 11 participated in the study. Adolescents were recruited from two high schools, situated in two different districts in The Netherlands. A total of eight classrooms took part in the study. Parents were informed through a letter and were able to withdraw their consent by instructing their child to turn in a blank questionnaire. Adolescents themselves could also decide to hand in a blank questionnaire. Of the 196 participating adolescents, only two returned an incomplete questionnaire and were excluded from further analysis.

All adolescents attended the general higher educational level (the Dutch HAVO and VWO). The mean age of the sample was 14.7 years $(S D=1.2$, range $=12-18)$. The sample consisted of 116 boys and 78 girls. Girls did not differ from boys in mean age.

\section{Measures}

\section{Bullying Behavior and Peer Victimization}

The Dutch KOP (Kinderen over Pesten [Children And Bullying]; De Bruin and Van Hattum 1999; Van Hattum 1997) was used to assess the extent to which adolescents bullied (the actor scale) and were bullied by others (the victim scale). The actor scale consisted of 15 items, and the victim scale consisted of 14 items. The KOP was adapted to an adolescent sample. Adolescents indicated whether an item described their situation on a five-point scale, ranging from "totally not true" to "totally true". The KOP contained items on both direct and indirect bullying (e.g., "Other students in my class often call me names", "I sometimes on purpose ignore other students"). Validity and reliability estimates of the KOP were good. Internal consistency was $\geq .90$, and test-retest correlations were sufficient for the victim scale, and good for the actor scale (De Bruin and Van Hattum 1999; Van Hattum 1997). The Cronbach alpha's in this study were good: .90 for the actor scale, and .92 for the victim scale.

\section{Depressive Symptoms}

Self-reported depressive symptoms were measured with the Dutch version (Van Leuven and Van Beek 2000) of the Children's Depression Inventory (CDI; Kovacs 1992). The 28 items of the CDI assessed different dimensions of depressive symptoms by asking respondents to choose between three statements, one for no depressive symptoms (score 0 ), one for mild symptoms (score 1), and one for severe depressive symptoms (score 2). Internal consistency and test-retest reliability of the CDI were good (see Van Beek et al. 2006). Internal consistency was $\geq .80$, and the test-retest correlation was .67. Reliability of the CDI in the present sample was good and consistent with previous research (Cronbach's alpha $=.84$ ).

\section{Personal Identity}

Adolescents' personal identity was measured with the Spatial Continuity of Identity Questionnaire (SCIQ; Van Hoof 1997, 1999; Van Hoof and Raaijmakers 2002). All adolescents described their identity in school, family, and leisure time contexts. Each context-specific identity was measured with 20 items which adolescents evaluated on a seven-point scale ranging from "I am totally not like that" to "I am totally like that". The 20 items represented four identity dimensions (Van Hoof 1997, Van Hoof and Raaijmakers 2002): Competence (four items: e.g. "I make/ take a decision easily"), Inhibition (six items: e.g. "I am insecure"), Feeling (four items: e.g. "I am lonely"), and Interpersonal Behavior (six items: e.g. "I do things without thinking beforehand about the possible danger or the consequences").

Each adolescent's evaluation of the 20 items for each of the three contexts was transformed into an intrapersonal matrix with the three identity contexts as the columns and the 20 items as the rows. The measure of spatial continuity, the Explanatory Power of the First Factor (EPFF: Epting et al. 1992), was calculated for each intrapersonal matrix $(N=194)$. The value of EPFF was calculated by factor analyzing the intra-individual matrix, and consisted of the percentage of the explained variance by the first factor. In case of strong relations between context-specific identities, the first factor obtained from this within-subject factor analysis accounted for a large percentage of the person's identity variance across contexts. In contrast, if a person's 
identity varies considerably across contexts, the first factor accounted for a small amount of variance in the intraindividual matrix (Cross et al. 2003; Suh 2002). The latent construct measured by this within subject factor analysis indicated the spatial continuity of the person: the higher the score, the more the person experienced a sense of spatial continuity (see: Dunkel 2005; Van Hoof 1997; Van Hoof and Raaijmakers 2002). In the present sample the EPFFscore ranged from .40 to $.99(M=.80, S D=.13)$.

\section{Family Cohesion and Family Disorganization}

The Leuven Family Questionnaire (LFQ) was used to measure family cohesion and family disorganization (Kog et al. 1985, 1987). The scales cohesion (subscale of family cohesion), and division (subscale of family disorganization) were selected. The subscale cohesion consisted of 13 items and measured the extent to which the adolescent experienced the family as a safe environment in which its members help and support each other (e.g. "I feel responsible for the other family members"; "In a discussion, parents and children are able to reach an agreement"). The subscale division consisted of 11 items and measured whether the adolescent perceived a lack of affective involvement and emotional bonds among family members (e.g. "Each of us leads our own life"; "We do not know whether we can count on each other"). All items were evaluated on a six-point scale. Reported validity and reliability estimates of the LFQ and its subscales were good. Internal consistency of the selected scales was .83 , and .86 respectively, and test-retest correlations were all higher than .70 (Vertommen et al. 1986). For the present sample, the internal consistency of cohesion and division was .84 and .82 , respectively.

\section{Results}

\section{Preliminary Analyses}

\section{Correlations Between Measures}

Correlations between measures are reported in Table 1. The mediating role of peer victimization in the relation between bullying behavior and depressive symptoms required that both bullying behavior and peer victimization were related to depressive symptoms, and that bullying behavior and peer victimization were interrelated. Likewise, the mediating role of personal identity in the relation between peer victimization and depressive symptoms required that both peer victimization and personal identity were related to depressive symptoms, and that peer victimization and personal identity were interrelated.

All correlations between measures of the mediation models were statistically significant. The correlation between two variables can also be interpreted in terms of effect size (Cohen 1988). Large effect sizes ( $r s>.50)$ were found for the relation between personal identity and depressive symptoms. The effect sizes of the other relations were medium to small ( $r s>.30$ and $r s>.10$ respectively). Medium effect sizes emerged for the relation between depressive symptoms and both family factors and peer victimization, and for the relations between identity and family factors. Small effect sizes appeared for the relations between family factors and both bullying behavior and peer victimization, and for the relations between bullying behavior and both personal identity and depression. Hence, the prerequisites for testing the mediation hypotheses were met (see Baron and Kenny 1986).

\section{Model Analyses}

The full model was analyzed using structural equation modeling (AMOS; Arbuckle 2006). The sample size of this study was sufficient to conduct structural equation modeling. Kline (1998) argued that a realistic and sufficient ratio of the number of respondents to the number of model parameters is 10:1. As the number of parameters to be freely estimated in this study was 17 , the sample size of 194 was sufficient for obtaining statistically stable results.

First, the two mediation models were tested separately, since inclusion of family characteristics and other explanatory factors might influence the results of each mediation model.

\section{Peer Victimization as Mediator Between Bullying and Depressive Symptoms}

The relation between bullying behavior and depressive symptoms was mediated by peer victimization. Modeling peer victimization as the mediator between bullying behavior and depressive symptoms diminished the relation between bullying behavior and depressive symptoms to statistically insignificant, and close to zero. Before mediation, the value of $B$ was $.06(S E=.029)$; after mediation this value changed to $.01(S E=.028) . \beta$ changed from .15 $(p=.034)$ to $.02(p=.799)$. The Sobel test (Preacher and Leonardelli 2007) revealed a statistically significant mediating effect of peer victimization (test statistic $=3.695, p<.001)$. 
Table 1 Correlations between measures and descriptive statistics (total sample, $N=194$ )

\begin{tabular}{|c|c|c|c|c|c|c|}
\hline & Family cohesion & Family disorganization & Bullying & Being victim & Identity & $\overline{\text { Depression }}$ \\
\hline Family cohesion & - & & & & & \\
\hline Family disorganization & $-.64 * * *$ & - & & & & \\
\hline Bullying & $-.24 * * *$ & $.27 * * *$ & - & & & \\
\hline Being victim & -.12 & $.29 * * *$ & $.31 * * *$ & - & & \\
\hline Identity & $.23 * *$ & $-.32 * * *$ & $-.17 *$ & $-.47 * * *$ & - & \\
\hline Depression & $-.36 * * *$ & $.44 * * *$ & $.15^{*}$ & $.43 * * *$ & $-.62 * * *$ & - \\
\hline Sample mean & 3.98 & 2.21 & 1.59 & 1.45 & 79.75 & .28 \\
\hline Standard deviation & .69 & .64 & .50 & .54 & 13.25 & .21 \\
\hline
\end{tabular}

$* p<.05, * * p<.01, * * * p<.001$

\section{Identity as Mediator Between Peer Victimization and Depressive Symptoms}

The relation between peer victimization and depressive symptoms was partially mediated by identity. Modeling identity as the mediator between peer victimization and depressive symptoms diminished the relation between peer victimization and depressive symptoms to less than half its former value. Before mediation, the value of $B$ was .16 $(S E=.025)$; after mediation this value changed to .07 $(S E=.024) . \quad \beta$ changed from $.43(p<.001)$ to .18 $(p=.004)$. The Sobel test (Preacher and Leonardelli 2007) revealed a statistically significant mediating effect of personal identity (test statistic $=5.406, p<.0001$ ).

\section{Full Model}

The results of the structural equation analysis of the full model for the total sample are presented in Fig. 2. The model showed a satisfactory fit (Goodness of fit: $\chi^{2}=6.64$, $d f=4, p=.156 ; A G F I=.94 ; N F I=.98 ; \quad R M S E A=$ .059), and explained about half of the variance in depressive symptoms $\left(M R^{2}\right.$ of depressive symptoms $\left.=.49\right)$.

The results demonstrated that the relation between bullying behavior and depressive symptoms is mediated by

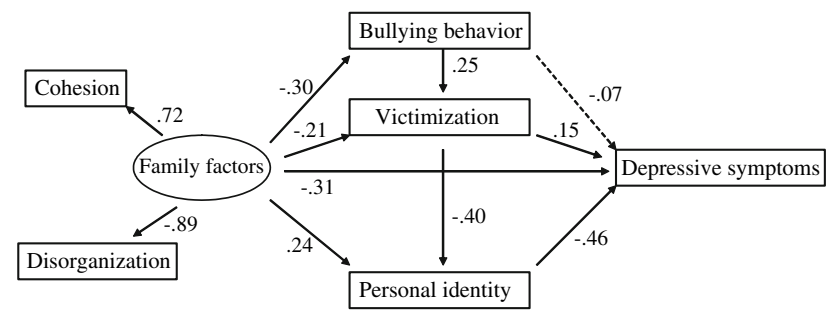

Fig. 2 Standardized estimates of the relations between family characteristics, bullying behavior, identity, and depressive symptoms for the total sample $(N=194)$. Broken lines indicate statistically insignificant paths $(p>.05)$ peer victimization: the direct effect of bullying behavior on depressive symptoms was smaller than its indirect effect ( -.027 versus .034, respectively). The results furthermore showed that the relationship between victimization and depressive symptoms was partly mediated by personal identity: the direct effect of peer victimization on depressive symptoms was smaller than its indirect effect (.057 versus .07, respectively). Finally, family characteristics were related to all variables in the model. The more positive the family characteristics, the less adolescents reported bullying behavior and peer victimization, and the more adolescents' personal identity was integrated. Noticeably, there was still a direct negative relation between family characteristics and depressive symptoms. The more positive family characteristics adolescents reported, the less they reported depressive symptoms. Although this direct effect of family characteristics on depressive symptoms was larger than its indirect effect $(-.128$ versus -.076 , respectively), one third of the relation between family characteristics and depressive symptoms was explained by the mediating variables in the model (i.e. bullying behavior, peer victimization, and personal identity).

\section{Discussion}

The first aim of the present study was to investigate whether peer victimization mediates the relation between bullying behavior and depression. The second aim was to test whether personal identity mediates the relation between peer victimization and depression. The third aim was to assess the relative importance of family characteristics on all variables included in both mediation models. It was hypothesized that family characteristics were related to all the variables in the model. The results of this study support both mediation models and the hypothesized influence of family characteristics. 
Bullying Behavior, Peer Victimization, and Depressive Symptoms

In this study, continuous measures were used to assess bullying behavior and peer victimization, which allowed for the analysis of the mediating effect of peer victimization at all levels of peer victimization. The results showed that the relation between bullying behavior and depressive symptoms was mediated by peer victimization. This indicates that the depressive symptoms of those who display bullying behavior stems from the extent to which they are simultaneously victimized by peers. Therefore, the results of this study suggest that bullying behavior is not, in itself, related to depressive symptoms.

The results of this study are consistent with the results of several previous studies. For instance, it is in line with findings that also failed to find a connection between bullying behavior and depressive symptoms (e.g., Juvonen et al. 2003; Solberg and Olweus 2003). It is also consistent with studies that found the association between bullying and depressive symptoms disappeared when controlled for being bullied (Van der Wal et al. 2003). Furthermore, there are studies using a bully/victim category that also found no relation between bullying and depressive symptoms (e.g., Fekkes et al. 2004).

Research using bully, victim, or bully/victim categories generally failed to control for all levels of peer victimization. Bully, victim, and bully/victim categorizations are often based on high levels of bullying behavior or/and high levels of peer victimization. It is possible that the modest relation between bullying and depressive symptoms reported in some of these studies would not have appeared had this relationship been corrected for all levels of peer victimization.

Peer Victimization, Personal Identity, and Depressive Symptoms

The results of the present study demonstrated the mediating function of personal identity for the relation between peer victimization and depressive symptoms. Although this mediation effect of personal identity was only partial, it still was statistically significant and substantial in terms of effect size. The indirect effect of peer victimization explained a larger amount of variance of depressive symptoms than the direct effect of peer victimization. This indicates that the contribution of peer victimization to the vulnerability for depressive symptoms is primarily based on its effects on the adolescent's identity. Adolescents who are victimized by peers have more trouble integrating their school, home, and leisure time identities into one coherent profile. This, in turn, makes them vulnerable for developing depressive symptoms.

\section{The Importance of Family Characteristics}

Family characteristics were related to all the variables of the model. The more family cohesion and affective involvement adolescents reported, the less they reported bullying behavior and peer victimization, and the more they displayed an integrated personal identity. In addition to the mediating functions of peer victimization, bullying behavior, and personal identity, the results also demonstrated the direct effect of family characteristics on depressive symptoms. We will now discuss the relation of family characteristics to each of the other constructs in our tested model.

In this study, family characteristics were related to bullying behavior in adolescents. The more adolescents reported family cohesion and family affect, the less they reported bullying behavior. This result is in line with similar results found in research with children (e.g., Berdondini and Smith 1996; Bowers et al. 1992; Stevens et al. 2002) despite the fact that the studies with children usually employ categorical measures of bullying behavior instead of the continuous measures used in this research.

This study also confirmed that the more adolescents reported emotional bonds between family members and the more they perceived family cohesion, the less they reported being a victim of bullying. These results thus support the conclusion that, in adolescence, family characteristics function as a protecting influence against peer victimization. Additionally, these results argue against the idea proffered in previous studies that high levels of family cohesion are indicative of over-protectiveness (e.g., Rigbee et al. 1999).

This study was the first to investigate the relationship between family environment and personal identity as a sense of temporal-spatial continuity. The positive relation between family environment and identity formation reported in studies using other measures of identity (e.g., Matheis and Adams 2004) was also found in the present study. The result indicates that family cohesion and family affect support the adolescent temporal-spatial continuity of identity.

It was remarkable that family characteristics, apart from their indirect effects, still showed a direct relation with depressive symptoms. The more supportive their family characteristics, the less adolescents reported depressive symptoms. The direct effect of family characteristics on adolescent depressive symptoms was larger than its indirect effect. This result either indicates the importance of family characteristics for adolescent depression or it 
demonstrates the need for studying additional mediating factors. This point will be returned to in our discussion of the limitations of our study.

\section{This Study's Model of Depressive Symptoms}

Zero-order correlations of depressive symptoms with family characteristics, personal identity, and peer victimization showed comparably moderate to strong associations. Yet, when the relations were studied simultaneously, family characteristics and personal identity appeared most strongly associated with depressive symptoms. This study indicates that the effect of peer victimization on adolescent psychological health for a substantial part is explained by its effect on personal identity. Personal identity thus played a crucial role in the study on the consequences of peer victimization and bullying behavior. Half of the variance in the reported depressive symptoms was explained by the model. The indirect effects of peer victimization and bullying behavior on depressive symptoms were larger than their direct effects, which underlines the mediating role of peer victimization and personal identity. Moreover, one third of the correlation between family factors and depressive symptoms was explained by the mediation of peer victimization and personal identity. The model was thus able to capture important processes concerning the dynamics of the relationship between family characteristics and depressive symptoms in adolescents.

\section{Limitations of the Study}

In the present study, adolescents' family characteristics, bullying behavior and victimization by peers, personal identity and depressive symptoms were all self-reported. The mono-informant character of the study could have positively influenced the moderate to strong relations between the constructs. Depressive symptoms could, for instance, bias the description of family characteristics and of victimization by peers. However, it is unlikely that the results are solely attributable to shared method variance, for the following three reasons.

The first reason has been presented by Hawker and Boulton (2000). They demonstrated that the mean effect sizes of the relation between peer victimization and depression was larger for studies with shared method variance than for studies without shared method variance. Still, their analyses showed that research that avoided shared method variance by using peer reports to study peer victimization also found a systematic relation between peer victimization and depression.
The second reason consists of two arguments in favor of valuing the perceived reports of adolescents in respect to family functioning more than the reports of parents. Firstly, adolescents' reports have more agreement with reports of outsiders than with reports of parents. Secondly, the effect of the subjective experience of family influences on adolescent development is stronger than the effect of parental reports on family functioning (e.g., Hale et al. 2007).

The third reason to diminish the importance of the possible effects of shared method variance was presented in the study by Magaro and Weisz (2006). They demonstrated that the experience of depression in children and adolescents did not taint their report of parental behaviors. The results of their study argue against the suggestion of spurious correlations between depressive symptoms and all forms of perceived parenting.

The present study confined the study of family functioning to the concepts of family cohesion and family affect. There are other family characteristics that have been studied in relation to bullying and peer victimization. For instance, empirical studies have shown that family violence, such as physical abuse, parental maltreatment, and witnessing parental violence, are related to bullying behavior and peer victimization (e.g., Baldry 2003; Shields and Cicchetti 2001). Future studies could include the influence of these and other family characteristics.

The full model in this study explained half of the variance in depressive symptoms. Inherent to a mediation model is that it cannot include all processes and constructs that explain vulnerability for depressive symptoms. Future studies might focus on other mediators in relation to peer victimization or family characteristics and depressive symptoms. In addition, moderating influences on the model were not tested in this study as the sample size did not allow for multi-group structural equation modeling. Future studies using larger sample sizes could address possible age or gender differences.

In the present study, the two mediation models and the relative influence of family characteristics were assessed at the same point in time. On the conceptual level, the first mediation model might accurately be tested in a crosssectional design. However, a longitudinal design of the first mediation model could add knowledge on the origin of the relation between bullying and victimization. It might for instance show how and when those victimized by peers start to show bullying behavior, and vice versa.

However, the second mediation model is best tested in a longitudinal design. Such a design makes it possible to examine the long-term effects of peer victimization on identity, or of a diminished personal continuity of identity on depressive symptoms. In addition, alternative explanations in terms of other directions between the variables tested in the second mediation model can be verified or 
falsified in a longitudinal design. In sum, a longitudinal design has the potential to determine whether depressive symptoms are a consequence, a predictor, or both consequence and predictor of personal identity.

\section{Conclusion}

This study examined the contribution of several important risk factors for adolescent depression development in one and the same model. The full model presented in this study explained half of the variance in adolescent depressive symptoms, an impressive finding in light of previous studies in this field. The results of this study demonstrated that bullying behavior is not, in itself, related to depressive symptoms. When bullying behavior and peer victimization are analyzed together in the same model, only peer victimization appears to influence adolescent depressive symptoms. Personal identity partly explained this relation between adolescent peer victimization and depressive symptoms. Moreover, the results of this study suggest that family characteristics, such as family cohesion and family affect, not only have a protective influence on bullying behavior, peer victimization and depressive symptoms, but also positively enhance personal identity formation. Hence, this study supports the position that positive family characteristics and a developed personal identity protect adolescents from the effects of peer victimization regarding the prevalence of depressive symptoms.

Open Access This article is distributed under the terms of the Creative Commons Attribution Noncommercial License which permits any noncommercial use, distribution, and reproduction in any medium, provided the original author(s) and source are credited.

\section{References}

Arbuckle, J. L. (2006). Amos 7.0 Programming reference guide.

Adams, G. R., Berzonsky, M. D., \& Keating, L. (2006). Psychosocial resources in first-year University students: The role of identity processes and social relationships. Journal of Youth and Adolescence, 35, 81-91.

Baldry, A. C. (2003). Bullying in schools and exposure to domestic violence. Child Abuse \& Neglect, 27, 713-732.

Baron, R. M., \& Kenny, D. A. (1986). The moderator-mediator variable distinction in social psychological research: Conceptual, strategic, and statistical considerations. Journal of Personality and Social Psychology, 51, 1173-1182.

Berdondini, L., \& Smith, P. K. (1996). Cohesion and power in the families of children involved in bully/victim problems at school: An Italian replication. Journal of Family Therapy, 18, 99-102.

Bond, L., Carlin, J. B., Thomas, L., Rubin, K., \& Patton, G. (2001). Does bullying cause emotional problems? A prospective study of young teenagers. British Medical Journal, 323, 480-484.

Bosworth, K., Espelage, D. L., \& Simon, T. R. (1999). Factors associated with bullying behavior in middle school students. Journal of Early Adolescence, 19, 341-362.
Bowers, L., Smith, P. K., \& Binney, V. (1992). Cohesion and power in the families of children involved in bully/victim problems at school. Journal of Family Therapy, 14, 371-387.

Cohen, J. (1988). Statistical power analysis for the behavioral sciences (2nd ed.). Hillsdale: Lawrence Erlbaum.

Côté, J. E., \& Levine, C. (1987). A formulation of Erikson's theory of ego identity formation. Developmental Review, 7, 273-325.

Craig, W. M. (1998). The relationship among bullying, victimization, depression, anxiety, and aggression in elementary school children. Personality and Individual Differences, 24, 123-130.

Cross, S. E., Gore, J. S., \& Morris, M. L. (2003). The relationinterdependent self-construal, self-concept consistency, and well-being. Journal of Personality and Social Psychology, 85, 933-944.

De Bruin, I., \& Van Hattum, M. J. C. (1999). Pesten. Een onderzoek naar de betrouwbaarheid en validiteit van de vragenlijst Kinderen over Pesten. [Bullying. A study on the reliability and validity of the children and bullying questionnaire]. Nederlands Tijdschrift voor Opvoeding, Vorming en Onderwijs, 15, 16-27.

Dunkel, C. S. (2005). The relation between self-continuity and measures of identity. Identity: An International Journal of Theory and Research, 5, 21-34.

Epting, F. R., Prichard, S., Wiggins, S. C., Leonard, J. A., \& Beagle J. W. Jr. (1992). Assessment of the first factor and related measures of construct differentiation. International Journal of Personal Construct Psychology, 5, 77-94.

Fekkes, M., Pijpers, F. I. M., \& Verloove-Vanhorick, S. P. (2004). Bullying behavior and associations with psychosomatic complaints and depression in victims. The Journal of Pediatrics, 144, $17-22$.

Garber, J., \& Flynn, C. (2001). Vulnerability to depression in childhood and adolescence. In R. E. Ingram \& J. M. Price (Eds.), Vulnerability to psychopathology. Risk across the lifespan (pp. 175-225). New York: The Guilford Press.

Hale W. W. III, Raaijmakers, Q. A. W., Gerlsma, C., \& Meeus, W. (2007). Does the level of expressed emotion (LEE) questionnaire have the same structure for adolescents as it has for adults? Social Psychiatry and Psychiatric Epidemiology, 42, 215-220.

Hawker, D. S. J., \& Boulton, M. J. (2000). Twenty years' research on peer victimization and psychosocial maladjustment: A metaanalytic review of cross-sectional studies. Journal of Child Psychology and Psychiatry, 41, 441-455.

Haynie, D. L., Nansel, T., Eitel, P., Crump, A. D., Saylor, K., Yu, K., \& Simons-Morton, B. (2001). Bullies, victims, and bully/ victims: Distinct groups of at-risk youth. Journal of Early Adolescence, 21, 29-49.

Juvonen, J., Graham, S., \& Schuster, M. A. (2003). Bullying among young adolescents: The strong, the weak, and the troubled. Pediatrics, 112, 1231-1237.

Juvonen, J., Nishina, A., \& Graham, S. (2000). Peer harassment, psychological adjustment, and school functioning in early adolescence. Journal of Educational Psychology, 92, 349-359.

Kaltiala-Heino, R., Rimpela, M., Rantanen, P., \& Rimpela, A. (2000). Bullying at school - an indicator of adolescents at risk for mental disorders. Journal of Adolescence, 23, 661-674.

Kline, R. B. (1998). Principles and practice of structural equation modeling. New York: The Guilford Press.

Kog, E., Vertommen, H., \& Degroote, T. (1985). Family interaction research in anorexia nervosa: The use and misuse of a family questionnaire. International Journal of Family Psychiatry, 6, 227-243.

Kog, E., Vertommen, H., \& Vandereycken, W. (1987). Minuchin's psychosomatic family model revised: A concept-validation study using a multitrait-multimethod approach. Family Process, 26, 235-253. 
Kovacs, M. (1992). Children's Depression Inventory, manual. New York/Toronto: Multi-Health Systems.

Kumpulainen, K., \& Rasanen, E. (2000). Children involved in bullying at elementary school age: Their psychiatric symptoms and deviance in adolescence. Child Abuse \& Neglect, 24, 1567-1577.

Magaro, M. M., \& Weisz, J. R. (2006). Perceived control mediates the relation between parental rejection and youth depression. Journal of Abnormal Child Psychology, 34, 867-876.

Matheis, S., \& Adams, G. R. (2004). Family climate and identity style during late adolescence. Identity: An International Journal of Theory and Research, 4, 77-95.

Nolan, S. A., Flynn, C., \& Garber, J. (2003). Prospective relations between rejection and depression in young adolescents. Journal of Personality and Social Psychology, 85, 745-755.

Preacher, K. J., \& Leonardelli, G. J. (2007). Calculation for the Sobel Test. An interactive calculation tool for mediation tests. http://www.psych.ku.edu/preacher/sobel/sobel.htm. Retrieved 23 April 2007.

Rigby, K. (1994). Psychosocial functioning in families of Australian adolescent schoolchildren involved in bully/victim problems. Journal of Family Therapy, 16, 173-187.

Rigbee, K. (2003). Consequences of bullying in schools. Canadian Journal of Psychiatry, 48, 583-590.

Rigbee, K., Slee, P., \& Cunningham, R. (1999). Effects of parenting on the peer relations of Australian adolescents. The Journal of Social Psychology, 139, 387-388.

Schwartz, D., Gorman, A. H., Nakamoto, J., \& Toblin, R. L. (2005). Victimization in the peer group and children's academic functioning. Journal of Educational Psychology, 97, 425-435.

Shields, A., \& Cicchetti, D. (2001). Parental maltreatment and emotion dysregulation as risk factors for bullying and victimization in middle childhood. Journal of Clinical Child Psychology, 30, 349-363.

Sitarenios, G., \& Kovacs, M. (1999). Use of the Children's Depression Inventory. In: M. Maruish (Ed.), The use of psychological testing for treatment planning and outcomes assessment (2nd ed.) (pp. 267-298). Mahwah: Lawrence Erlbaum.

Slee, P. T. (1995). Peer victimization and its relationship to depression among Australian primary school students. Personality and Individual Differences, 18, 57-62.

Snarey, J., Kohlberg, L., \& Noam, G. (1983). Ego development in perspective: Structural stage, functional phase, and cultural ageperiod models. Developmental Review, 3, 303-338.

Solberg, M. E., \& Olweus, D. (2003). Research on school bullying and victimization: What have we learned and where do we go from here? School Psychology Review, 32, 365-384.

Stevens, V., De Bourdeaudhuij, I., \& Van Oost, P. (2002). Relationship of the family environment to children's involvement in bully/victim problems at school. Journal of Youth and Adolescence, 31, 419-428.

Suh, E. M. (2002). Culture, identity consistency, and subjective wellbeing. Journal of Personality and Social Psychology, 83, 13781391.

Troop-Gordon, W., \& Ladd, G. W. (2005). Trajectories of peer victimization and perceptions of the self and schoolmates: Precursors to internalizing and externalizing problems. Child Development, 76, 1072-1091.

Van Beek, Y., Van Dolderen, M. S. M., \& Demon Dubas, J. J. S. (2006). Gender-specific development of nonverbal behaviours and mild depression in adolescence. Journal of Child Psychology and Psychiatry, 47, 1272-1283.

Van der Wal, M. F., de Wit, C. A. M., \& Hirasing, R. A. (2003). Psychosocial health among young victims and offenders of direct and indirect bullying. Pediatrics, 111, 1312-1317.
Van Hattum, M. J. C. (1997). Pesten. Een onderzoek naar beleving, visie en handelen van leraren en leerlingen. [Bullying. A study on the perception, cognition and handling of teachers and students]. Unpublished doctoral dissertation, The Netherlands: Utrecht University.

Van Hoof, A. (1997). Identity formation in adolescence: Structural integration and guiding influences. Unpublished doctoral dissertation, Utrecht: Utrecht University.

Van Hoof, A. (1999). The identity status approach: In need of fundamental revision and qualitative change. Developmental Review, 19, 622-647.

Van Hoof, A., \& Raaijmakers, Q. A. W. (2002). The spatial integration of adolescent identity: Its relation to age, education, and subjective well-being. Scandinavian Journal of Psychology, $43,201-212$.

Van Hoof, A., \& Raaijmakers, Q. A. W. (2003). The search for the structure of identity formation. Identity: An International Journal of Theory and Research, 3, 271-289.

Van Leuven, M., \& Van Beek, Y. (2000). Children's Depression Inventory, Nederlandse Bewerking. Internal Report, Utrecht: Utrecht University.

Vertommen, H., Kog, E., \& Degroote, T. (1986). Leuvense Gezinsvragenlijst. Handleiding. [Leuven Family Questionnaire. Manual]. Lisse: Swets \& Zeitlinger.

\section{Author Biographies}

Dr. Anne van Hoof is an Assistant Professor at the Department of Developmental Psychology at Utrecht University, the Netherlands. She received her Ph.D. in Psychology from the same University. Her major research interests include adolescent identity development and moral development, civic pro-social behavior, and bullying.

Dr. Quinten A. W. Raaijmakers is an Associate Professor at Utrecht University (the Netherlands). He received his Ph.D. in Psychology from the same university. His major research interests include sociomoral identity development in adolescents, adolescent adjustment and methods and statistics.

Dr. Yolanda van Beek Human ethologist working at the Department of Developmental Psychology of the Utrecht University in the Netherlands. Her primary research interests include the development of nonverbal communication skills and developmental psychopathology. Her current research project focuses on the link between depression and the development of nonverbal behavior and emotion decoding in adolescence.

Dr. William W. Hale III a clinical psychologist, is an Assistant Professor at the Research Center for Adolescent Development, Utrecht University, the Netherlands. He obtained his Ph.D. at the Department of Biological Psychiatry, University of Groningen in 1997, on his work on non-verbal behaviors and clinical depression. Since then he has worked as both an assistant professor and a cognitive-behavioral therapist for the University of Maastricht and later for Utrecht University. Currently, he is involved in research on adolescent depression and anxiety, and the effects parental factors have on these pathologies.

Dr. Liesbeth Aleva is an Assistant Professor at Utrecht University. She received her Ph.D. in Developmental Psychology from the Utrecht University. Her major research interests include social competence, peer relations, social withdrawal, and bullying in children. 